$16^{\text {th }}$ International Conference on

AEROSPACE SCIENCES \& AVIATION TECHNOLOGY,

$\boldsymbol{A S A T}$ - 16 - May 26 - 28, 2015, E-Mail: asat@mtc.edu.eg

Military Technical College, Kobry Elkobbah, Cairo, Egypt

Tel : +(202) 24025292 - 24036138, Fax: +(202) 22621908

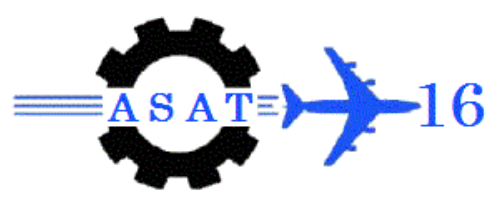

\title{
Numerical Study of the Semi-Open Centrifugal Pump Impeller Side Clearance
}

\author{
A. Farid Ayad*, H. M. Abdalla ${ }^{\dagger}, A$. S. Abo El-Azm \\ Egyptian Armed Forces, Egypt
}

\begin{abstract}
The effect of impeller side clearance (the gap between the impeller face and the casing) on the centrifugal pump performance has been investigated numerically through monitoring the change of the pump head and efficiency at different flowrate. 3-D numerical simulation has been carried out using commercial software, ANSYS $®$ CFX. The numerical simulation has been compared with experimental results to verify the numerical solution. In addition, the results have been compared with the closed impeller with front shroud at the same operating conditions It has been shown that the impeller side clearance have a great regression effect on the centrifugal pump performance. This regression on performance could be attributed to the drop in the pressure difference between the impeller inlet and outlet. And the secondary flow across the blade tip which impedes the core flow.
\end{abstract}

Keywords: Computational Fluid Dynamics (CFD), Impeller Side Clearance, Centrifugal Pump Performance, semi-open impeller.

$\begin{array}{cl}\text { Nomenclature } \\ \mathrm{b} & \text { Blade width } \\ C & \text { Absolute velocity } \\ D & \text { Impeller diameter } \\ e & \text { Side clearance width } \\ g & \text { Gravitational acceleration } \\ H & \text { Pump head } \\ n & \text { Rotational speed } \\ n & \text { Area vector } \\ p & \text { Pressure } \\ P & \text { Power } \\ Q & \text { Volumetric flow rate } \\ \mu & \text { Slip factor (European definition) } \\ \rho & \text { Fluid density } \\ \sigma & \text { Slip factor (American definition) } \\ \nu & \text { kinematic viscosity } \\ \tau & \text { Shear stress } \\ \tau^{R} & \text { Reynolds-stress tensor } \\ \omega & \text { Impeller angular velocity } \\ \Delta C_{u} & \text { Slip velocity }\end{array}$

$\begin{array}{cl}r & \text { Radius } \\ S_{\mathrm{M}} & \text { Source term } \\ t & \text { Blade thickness } \\ \mathrm{U} & \text { Peripheral velocity } \\ u & \text { Flow velocity vector field } \\ W & \text { Relative velocity } \\ Z & \text { Blades number } \\ \Delta Z & \text { Potential head } \\ \text { Greeks } & \\ \beta & \text { Blade angle } \\ \eta & \text { Efficiency } \\ \mathrm{m} & \text { Mechanical } \\ \mathrm{v} & \text { Volumetric } \\ \mathrm{w} & \text { Wall } \\ \text { imp } & \text { Related to impeller } \\ \mathrm{BEP} & \text { Best efficient point } \\ \text { exp } & \text { experimental } \\ \text { thœ } & \text { Theoretical with infinite blades number } \\ \mathrm{u} & \text { Circumferential component }\end{array}$

\footnotetext{
* Post graduate student, Aerospace Department, a.farid.mtc@gmail.com

${ }^{\dagger}$ Ass. Prof, Aerospace Department

$\$$ Ass. Prof, Mechanical Power Department, Aboazm2005@yahoo.com
} 


$\begin{array}{cl}\text { Subscripts } & \\ 1 & \text { Impeller inlet } \\ 2 & \text { Impeller outlet } \\ \text { d } & \text { Delivered } \\ \text { s } & \text { Suction } \\ \text { in } & \text { Pump inlet } \\ \text { out } & \text { Pump outlet } \\ \text { el } & \text { Electric }\end{array}$

$\begin{array}{cl}\text { R } & \text { Radial component } \\ \text { e } & \text { For certain side clearance width } \\ \text { H } & \text { Related to head } \\ \Delta & \text { Related to velocity triangle } \\ \text { Superscripts } \\ \quad \text { Real flow } \\ \text { - } \\ \text { - } & \text { Mean value }\end{array}$

\section{Introduction}

Centrifugal pumps are probably among the most often used machinery in industrial facilities as well as in common practice. According to the used impeller type, centrifugal pump can be classified to closed, semi open and open impeller[1].

Some of rocket engine with turbo-pump feeding system are used centrifugal pump with semi open impeller. The main reason to use this type of impeller in the rocket engine design is reducing the weight and manufacturing complexity. As a pump spins faster, hoop stress due to centrifugal force in the impeller increases. The mass of the shroud increases the stress and limits the speed at which a pump can operate. A pump impeller without a shroud can operate at higher speeds with lower stress and generate more head [2].

The main advantages of semi-open centrifugal pump are: good hydraulic efficiency, less likely to clog with solids, it is easy to clean, has all the parts visible, so it's easy to inspect for wear or damage, low cost than closed impeller, The vanes can easily be cut or filed to increase the capacity and have a greater range of specific speed choices, The liquids handled by these impellers can have higher percentages of gases and solid particles than those carried by closed-type impellers. The main disadvantages of it are: less volumetric efficiency than the closed impeller, give higher axial thrust, has an operating temperature range, not well with volatile and explosive liquid.[3]

In the case of semi-open impellers fluid flows from the pressure to the suction surface of the blades through the side clearance. The leakage flow reinforces the secondary flow in the channel, imparting greater three-dimensionality to the flow in the impeller. Consequently efficiency and head suffer with growing clearance [4]. So, side clearance is very important factor to be considered when resorting to use centrifugal pump with semi-open impeller. Side clearance depends on manufacturing, pump size and pump material.

Robert W. Williams [2] studied three side clearances with CFD analysis and experiment at onand off- design conditions. Nine CFD analyses were completed. Operating conditions at $80 \%$, $100 \%$, and $120 \%$ of the design flow rate were examined for each of the three-side clearances width $(0.3,1.3$ and $1.8 \mathrm{~mm})$ for a $305 \mathrm{~mm}$ impeller outer diameter. Static pressures along the blade passage obtained from the CFD models were examined to determine blade stress and axial load.

Sebastien Aknouche [5] showed a computational study to evaluate the effect of Sideclearance on centrifugal pump impeller efficiency and Head. The important conclusion of this study is how author Interpreted the change in pump performance by two main reason: the first one is side clearance flow partially mixes with the core flow when it enter the channel. And the second one is resulting low streamwise velocity region is responsible for flow blocking and decreased pressure rise

In the present work, a parametric study is attempted, based on the Impeller side clearance to investigate the effect of the clearance width on the pump performance. The pump performance is investigated through monitoring the change of head and efficiency. The study implements a 3-D numerical simulation of turbulent flow inside the centrifugal pump. 


\section{Computational model}

\section{Geometrical Models}

The centrifugal pump with semi-open impeller shown in, Fig. 1 is chosen as a geometrical model to apply numerical computation. This impeller is designed based on single arc technique and manufacturing using $\mathrm{CNC}$ machine. The main metrics of pump impeller design are listed in Table (1).
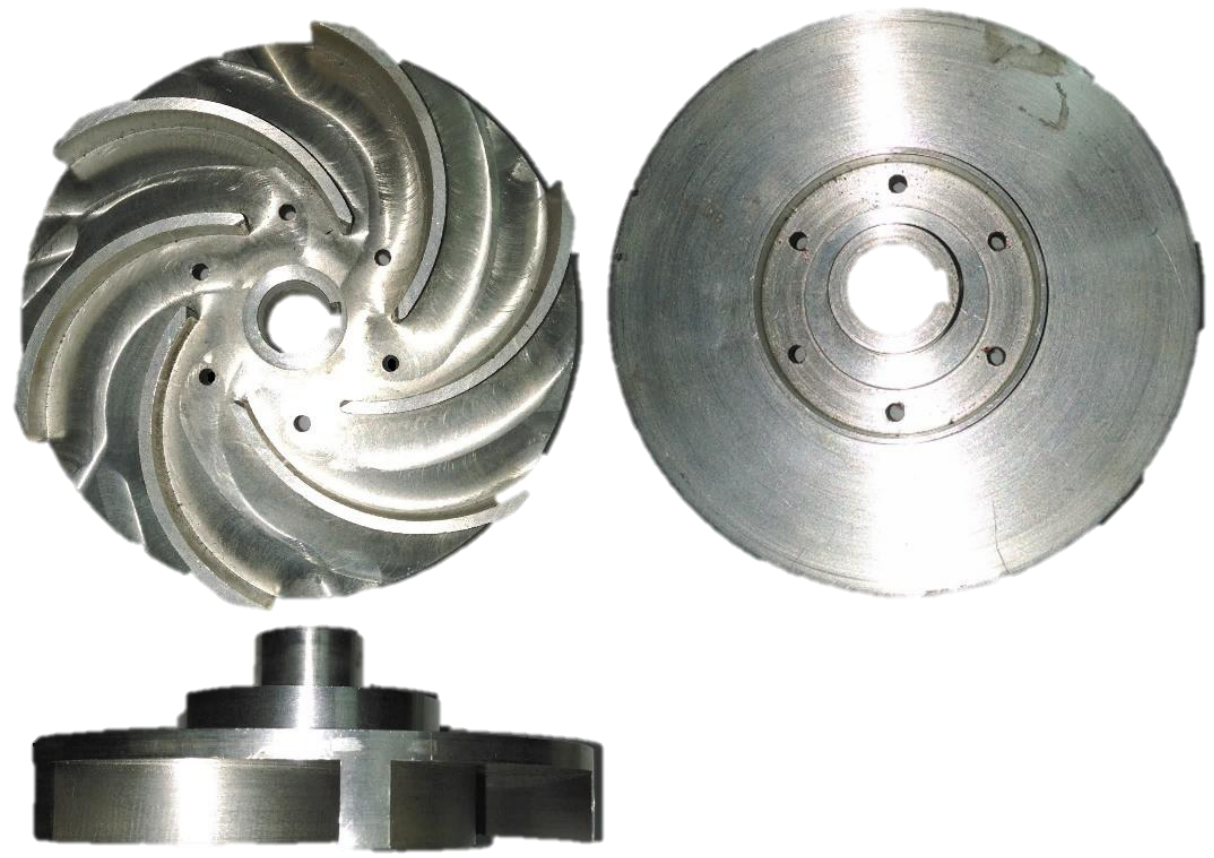

Fig. 1. Centrifugal impeller with backward blades

Two geometrical models have been generated. Model Ml represent the centrifugal pump with closed impeller. Model M2 represent the same pump with semi-open impeller.

Table (1) Pump impeller dimensions

\begin{tabular}{l||l|l||l}
\hline \hline Blades Number $(\mathrm{Z})$ & 6 & Blade discharge angle $\left(\beta_{2}\right)$ & $20^{\circ}$ \\
\hline Rotational Speed $(\mathrm{n})$ & $1500(\mathrm{rpm})$ & Blade inlet angle $\left(\beta_{1}\right)$ & $35^{\circ}$ \\
\hline Impeller Inlet Diameter $\left(\mathrm{D}_{1}\right)$ & $50(\mathrm{~mm})$ & Blade height $(\mathrm{b})$ & $15(\mathrm{~mm})$ \\
\hline Impeller Outlet Diameter $\left(\mathrm{D}_{2}\right)$ & $130(\mathrm{~mm})$ & Blade thickness $(\mathrm{t})$ & $2.5(\mathrm{~mm})$ \\
\hline \hline
\end{tabular}

\section{Governing Equations}

Numerical simulation is carried out using ANSYS 14.5 ${ }^{\circledR}$ CFX to solve the governing equations. Since the pumped fluid is incompressible and the flow is in a steady state, the continuity equation has the following form [6]:

$$
\nabla \cdot \overline{\mathbf{u}}=0
$$

In addition, the equation of conservation of momentum together with the definition of the source term, and the shear stress is expressed as Eq. (2)

$$
\nabla \cdot(\overline{\boldsymbol{u}} \overline{\boldsymbol{u}})=\frac{-\nabla \bar{p}}{\rho}+v \nabla^{2} \overline{\boldsymbol{u}}-\frac{1}{\rho} \nabla \cdot \boldsymbol{\tau}^{R}+S_{\mathrm{M}}
$$

where the source term (including the centrifugal and Coriolis force terms) is written as Eq. (3) and the Reynolds-stress tensor obtained from Eq. (4): 


$$
\begin{gathered}
S_{M}=-\rho[2 \boldsymbol{\omega} \times \mathbf{u}+\boldsymbol{\omega} \times(\boldsymbol{\omega} \times \mathbf{r})] \\
\boldsymbol{\tau}^{R}=-\rho \overline{\boldsymbol{u u}}
\end{gathered}
$$

\section{Computational Domain}

The computational domain consists of four zones: inlet, side gab, impeller and volute with outlet as shown in Fig. 2. They are defined by means of the multi-reference frame technique. The impeller is situated in the rotating reference frame, the inlet side gab and outlet zones are in the fixed reference frame, and they are related to each other through the "frozen rotor" interface [7], except the interface between the inlet and side gab is selected to be general connection.

\section{Domain Discretization}

The meshes of four computational domains are generated separately after performing mesh sensitivity analysis as shown in Fig. 3. In this analysis, localized refinements of mesh are employed at regions close to the impeller blade and the blade leading and trailing edges in order to accurately capture the dominant flow field structure. The motive of this localized mesh refinement is to encounter considerable variations of flow field properties such as pressure and velocity at those regions.

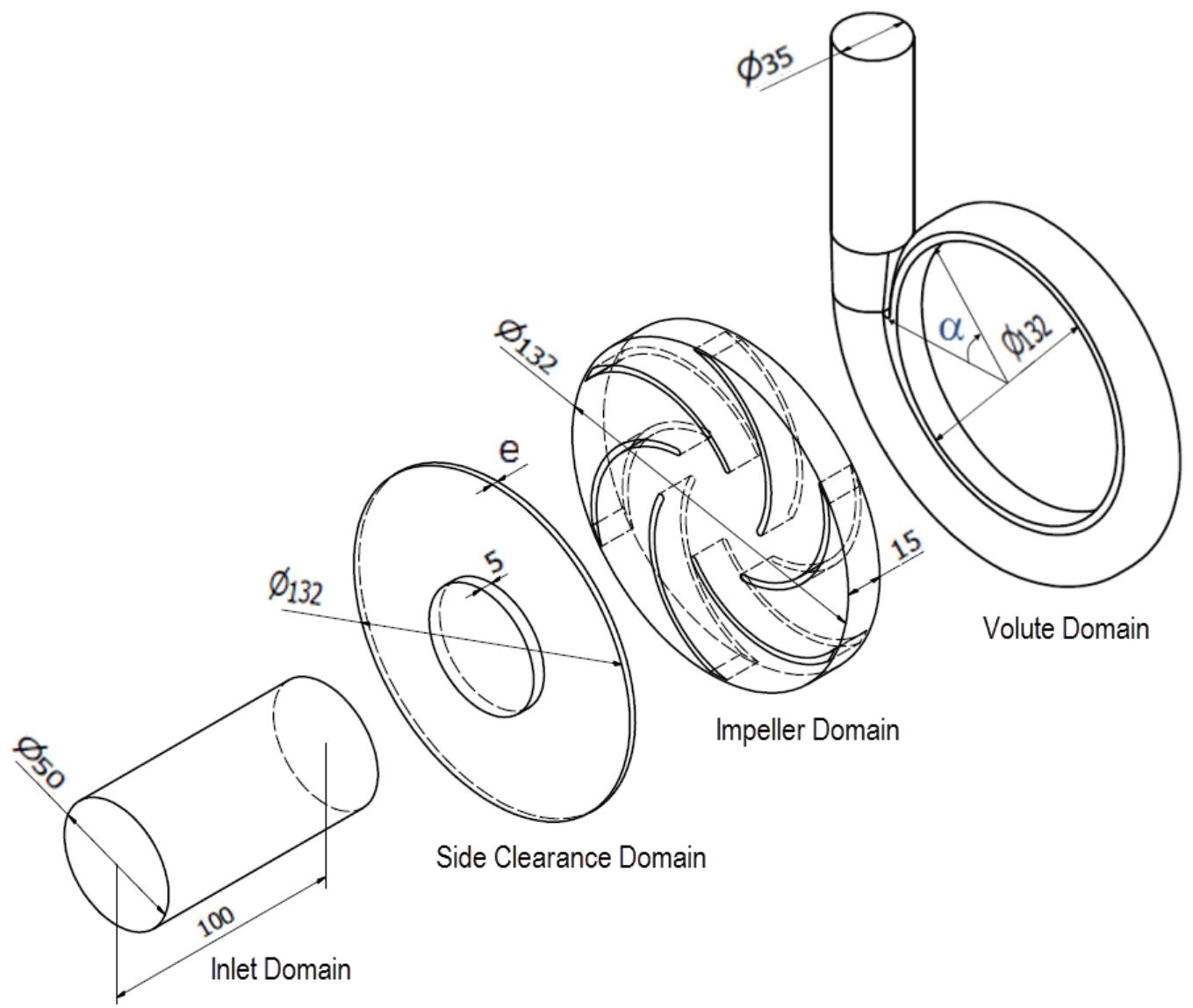

Fig. 2. Computational Domain (inlet-impeller-outlet) zones 


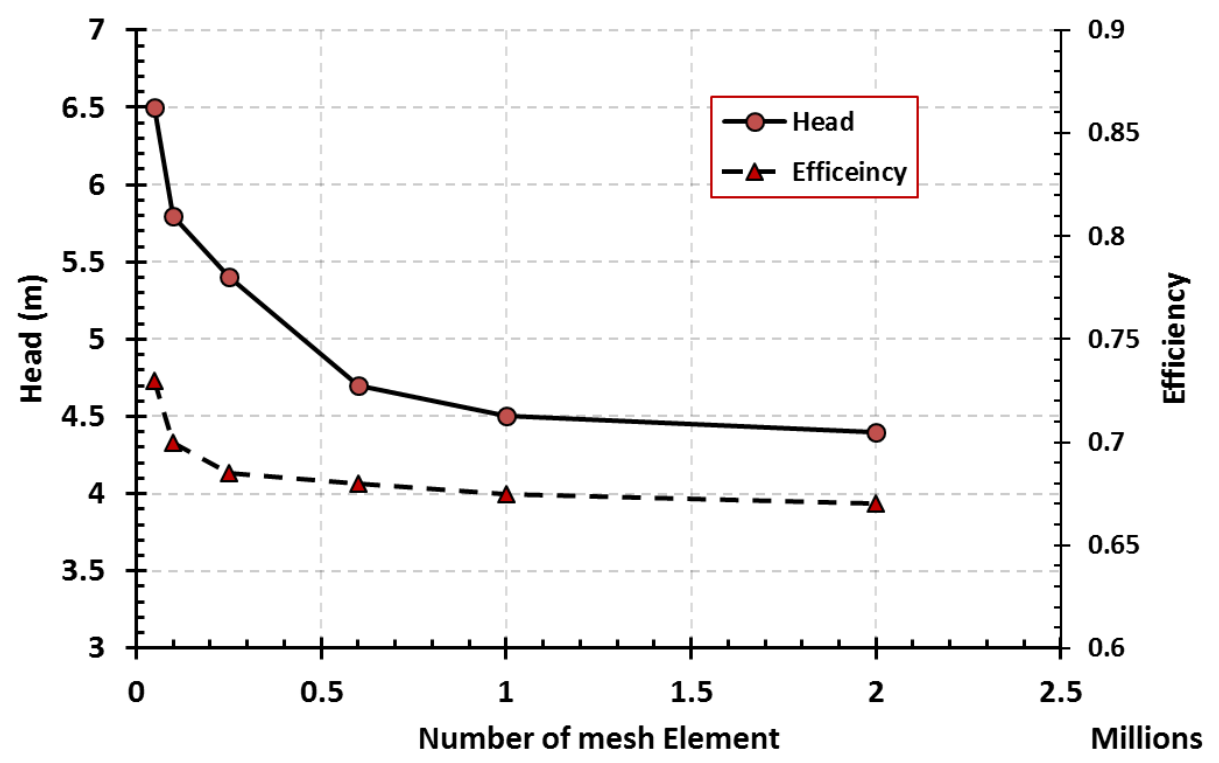

Fig. 3. Mesh sensitivity analysis for $M 2$ with $\mathrm{e}=2 \mathrm{~mm}, \mathrm{Q}=3.5 \mathrm{Liter} / \mathrm{s}$

Total number of mesh elements are about 600000 elements where, the inlet domains include 22200 hexahedrons element, impeller domain include 203868 tetrahedrons elements, the volute domain includes 300000 tetrahedrons elements, while the side gab domain elements number varying with the variation of side clearance width with average number of 100000 tetrahedrons elements as shown in Fig. 4. To cope with the complicated domain topology a combination of structured and unstructured grids is used.

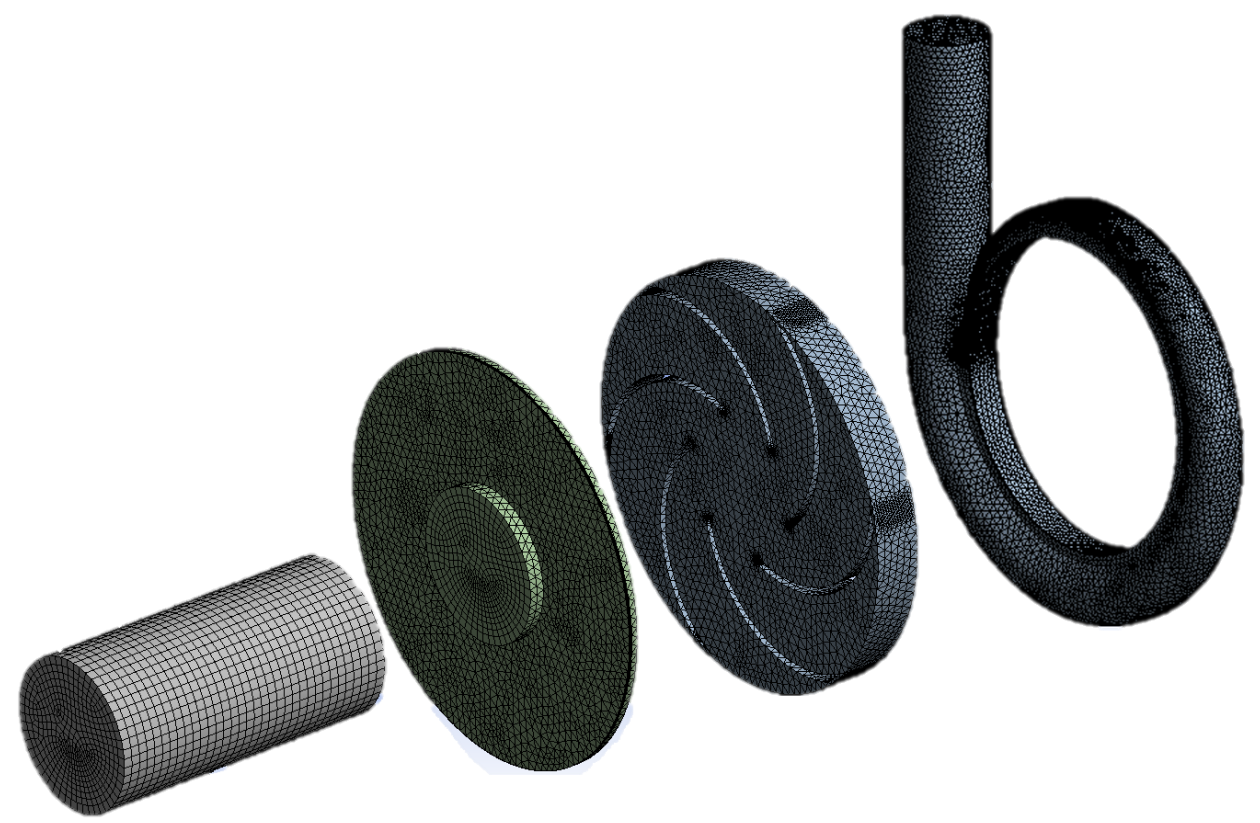

Fig. 4. Inlet, side gab impeller and volute domain mesh

\section{Boundary Conditions and Zones Interface}

The boundary conditions are set as total pressure at inlet and the mass flow at outlet. A no-slip condition is imposed at the wall boundary defined at the blade and casing. The impeller domain is modeled in the rotating frame, and the inlet, side gab and the volute domains are modeled in the fixed reference frame. Fig. 5 illustrate the definition of the boundary conditions. 


\section{Convergence Criteria of the Numerical Simulations}

The numerical solution has two condition to say that this solution is converged: the first one is the residuals become less than $10^{-5}$, and the second is the pump head value remains constant for at least hundreds of iteration. Fig. 6 shows an example of the history of convergence.

\section{Turbulence Model}

With the help of the mixing function value, the shear stress transport (SST) model automatically uses the $k-\omega$ model in the near-wall regions and the $k-\varepsilon$ model in the regions away from the wall. This model modifies the energy production term in the kinetic energy transfer equation [8]. Considering the studies conducted on the two models of $k-\varepsilon$ and $R N G k-\varepsilon$, it is concluded that the near-wall flow can be evaluated with high precision using the $k-\varepsilon$ model and the SST function. The obtained results show better accuracy than those of the $k-\varepsilon$ model alone. Therefore, the SST turbulence model is used for the numerical investigation of flow inside the centrifugal pump.

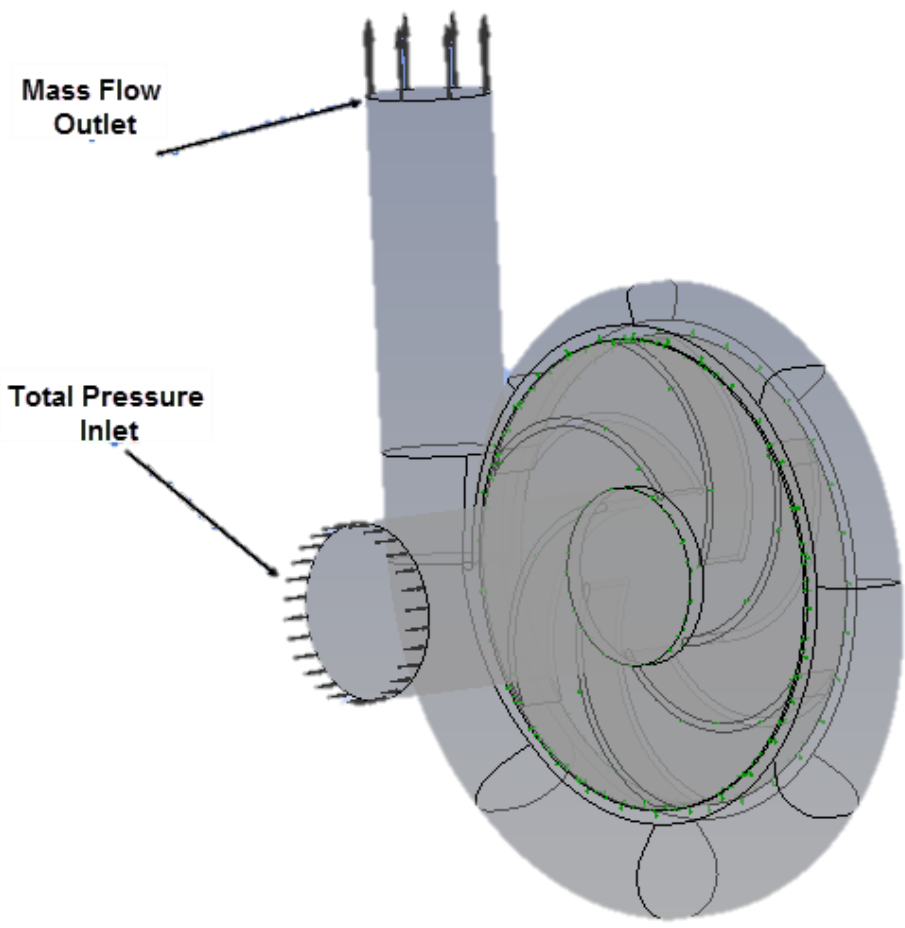

Fig. 5. Boundary conditions and zones interface 


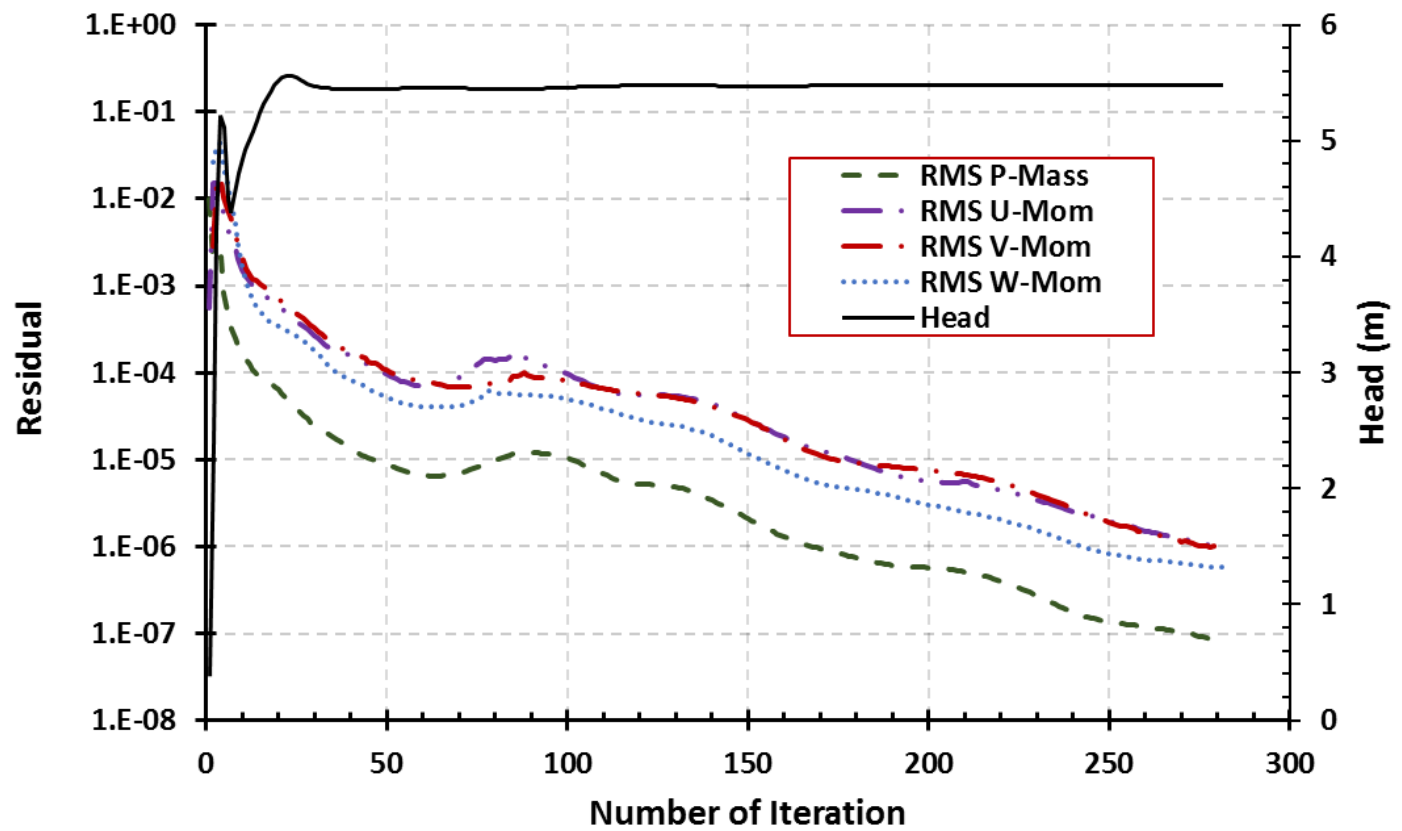

Fig. 6 Residual history versus number of iterations $(Q=3.5$ liter/s \& e = 1mm)

\section{Experimental work}

A centrifugal pump test rig, shown in Fig. 7, was used to validate the numerical solution. The main components of the centrifugal pump test rig and the measurement instruments are listed in Table 2. The investigated impeller is a six blades backward semi-open impeller. The full dimension of the impeller is shown in Fig. 8. The blade angle designed with the concept of single arc technique.

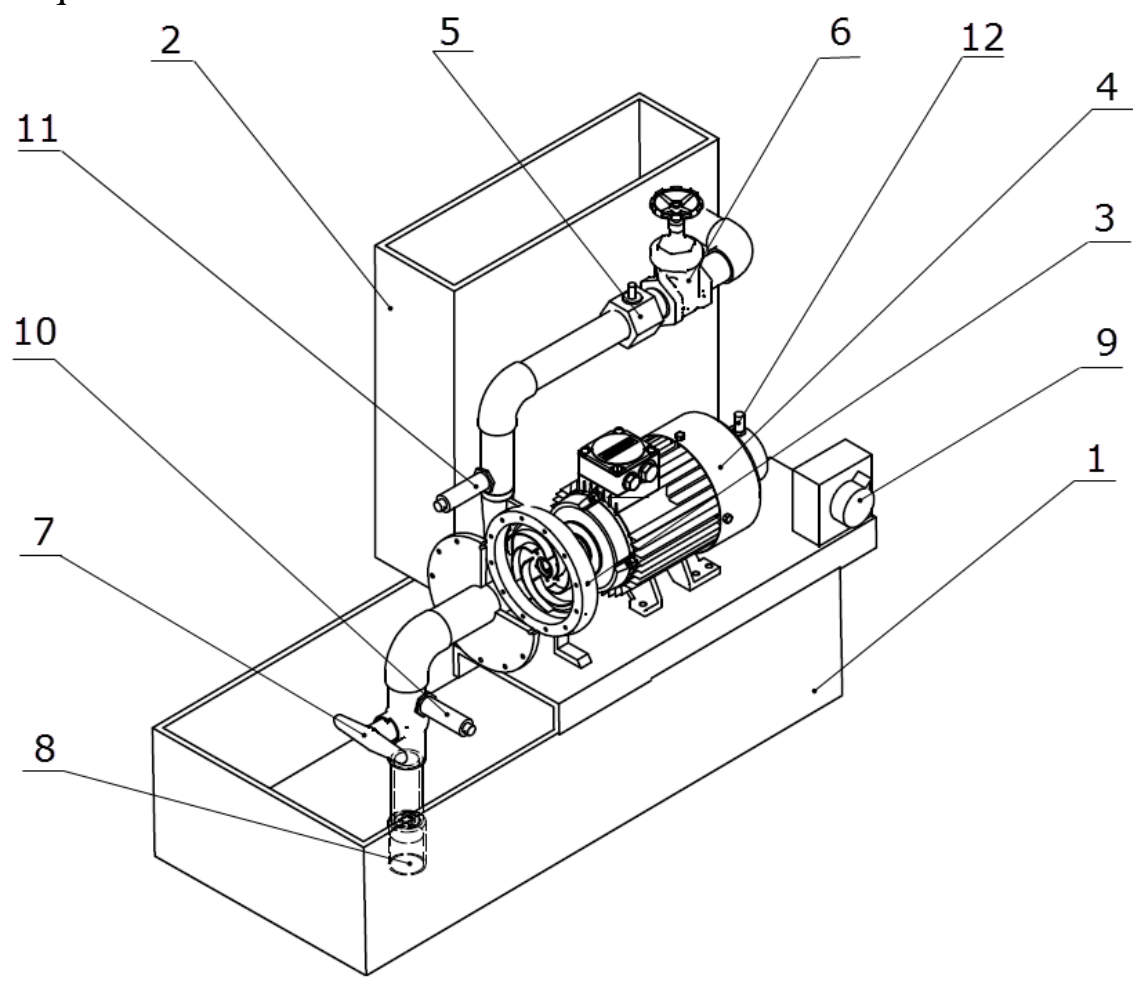

Fig. 7. Centrifugal pump test rig

Experiment was carried out at $1500 \mathrm{rpm}$ and the operation condition was controlled by a gate valve on the discharge pipe. Absolute pressure transducers (HBM P6A) with rated sensitivity $2 \mathrm{mV} / \mathrm{V}$ was used at the pump inlet and outlet pipes to measure the inlet and outlet pressures 
accurately. OMEGA FTB-109 turbine meters with shielded ball bearing has been used for flow rate measurements.

Table 2 Test rig main components

\begin{tabular}{l|l||l|l}
\hline \hline 1 & Sump Tank & 7 & Suction Valve \\
\hline 2 & Volumetric Measuring Tank & 8 & Foot Valve \\
\hline 3 & Centrifugal Pump & 9 & Speed Control Unit \\
\hline 4 & DC Motor & 10 & Suction Pressure Sensor \\
\hline 5 & Turbine Flow Meter & 11 & Delivery Pressure Sensor \\
\hline 6 & Delivery gate Valve & 12 & Electric Tachometer \\
\hline \hline
\end{tabular}

Here, the pump head and total system efficiency are calculated according to reference by using

Eq. (5) and Eq.(6), respectively

$$
\begin{gathered}
H=\frac{p_{d}}{\rho g}-\frac{p_{s}}{\rho g}+\left[\frac{v_{d}^{2}}{2 g}-\frac{v_{s}^{2}}{2 g}\right]+\Delta Z \\
\eta_{t}=\frac{P_{\text {out }}}{P_{\text {in }}}=\frac{\rho g H Q}{V I}
\end{gathered}
$$
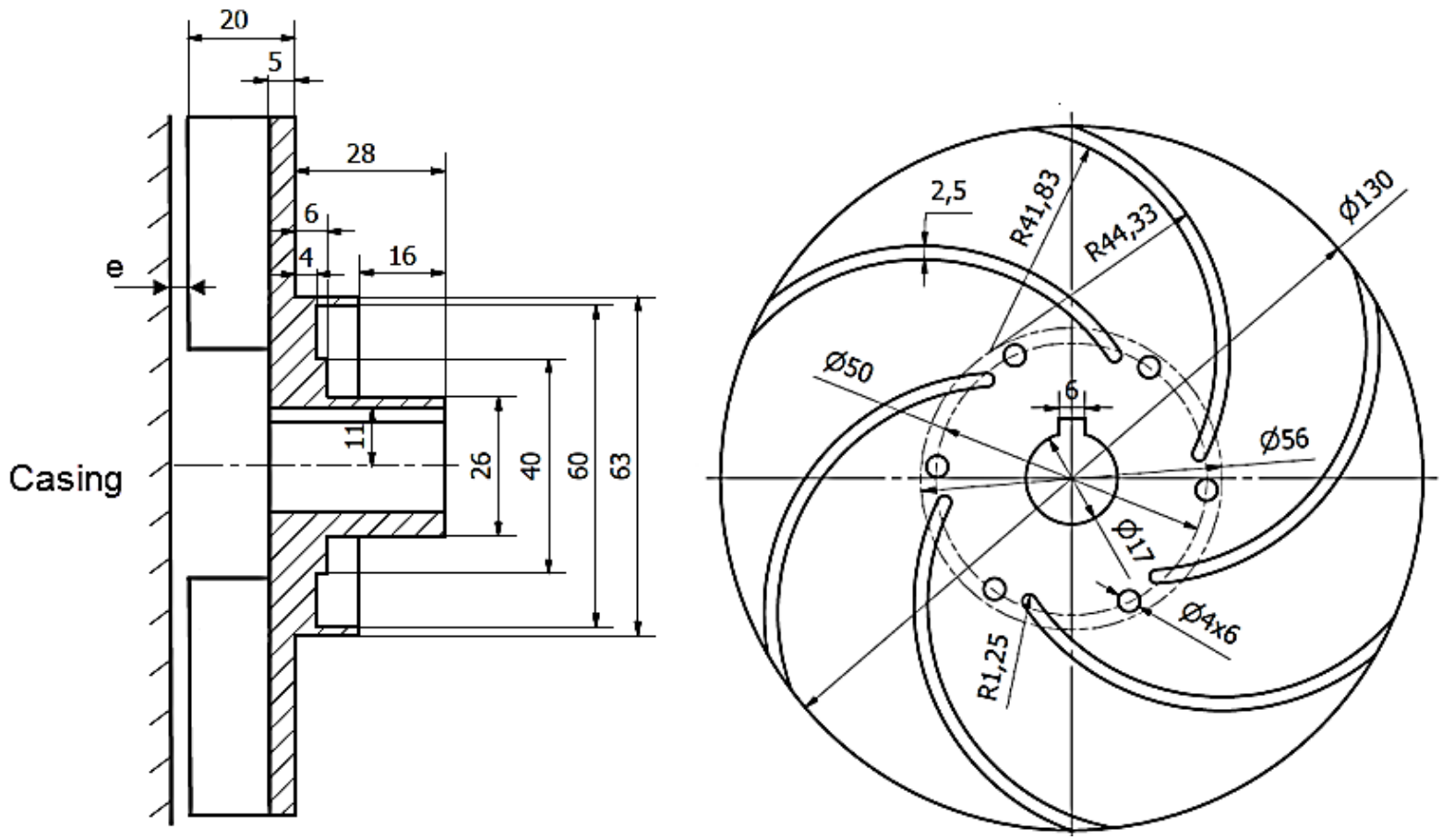

Fig. 8. Semi-open impeller dimension

The result of the experimental including the head and total efficiency of centrifugal pump with semi-open impeller are shown in figure Fig. 9. 


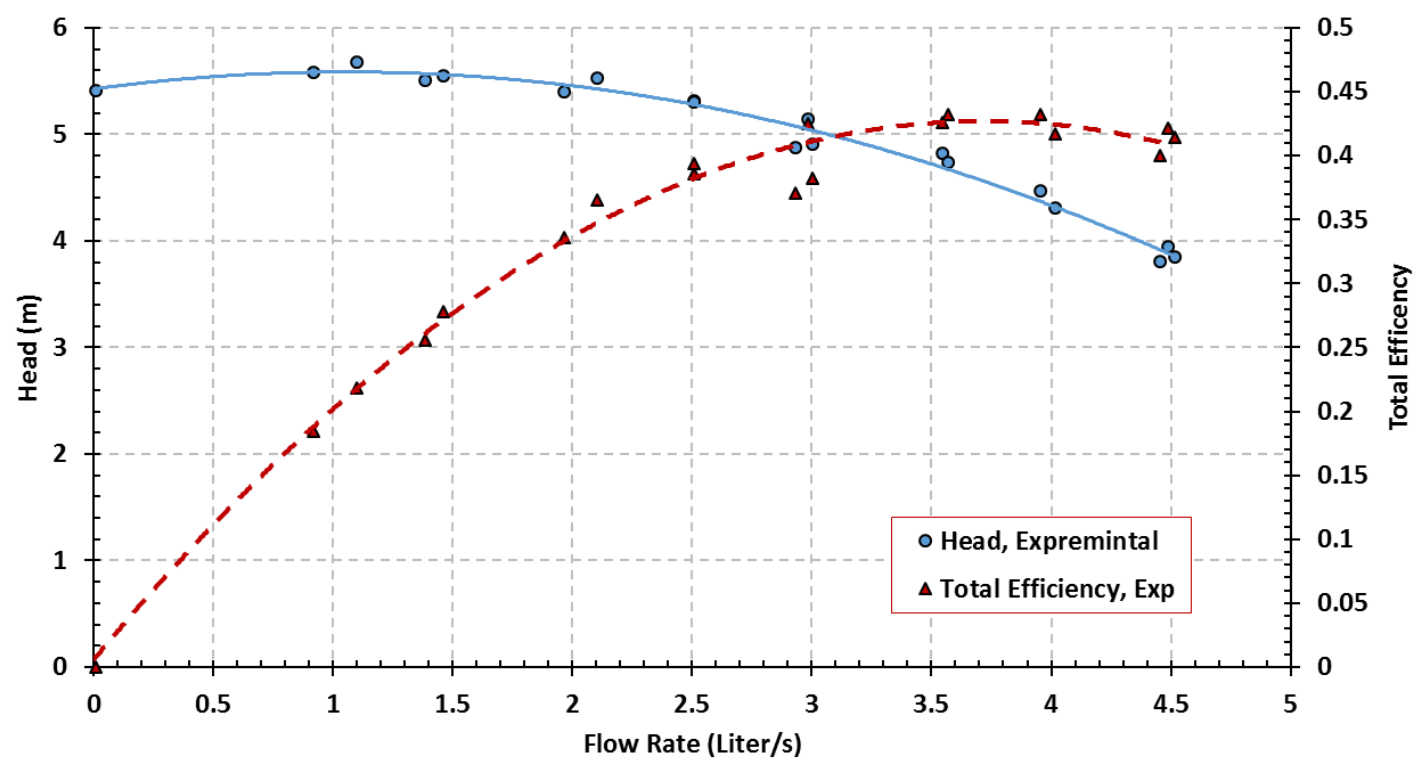

Fig. 9. Experimental performance of centrifugal pump $(\mathrm{n}=1500 \mathrm{rpm}) \mathrm{e}=1 \mathrm{~mm}$

The comparison between the experimentally measured and computational results of the pump performances with semi-open impeller is used to validate the present study as shown in, Fig. 10. The test rig which is used in the experiment is installed with impeller side clearance of 1 $\mathrm{mm}$, and the computational study discuss the impeller with side clearance of 1,2 and $3 \mathrm{~mm}$.

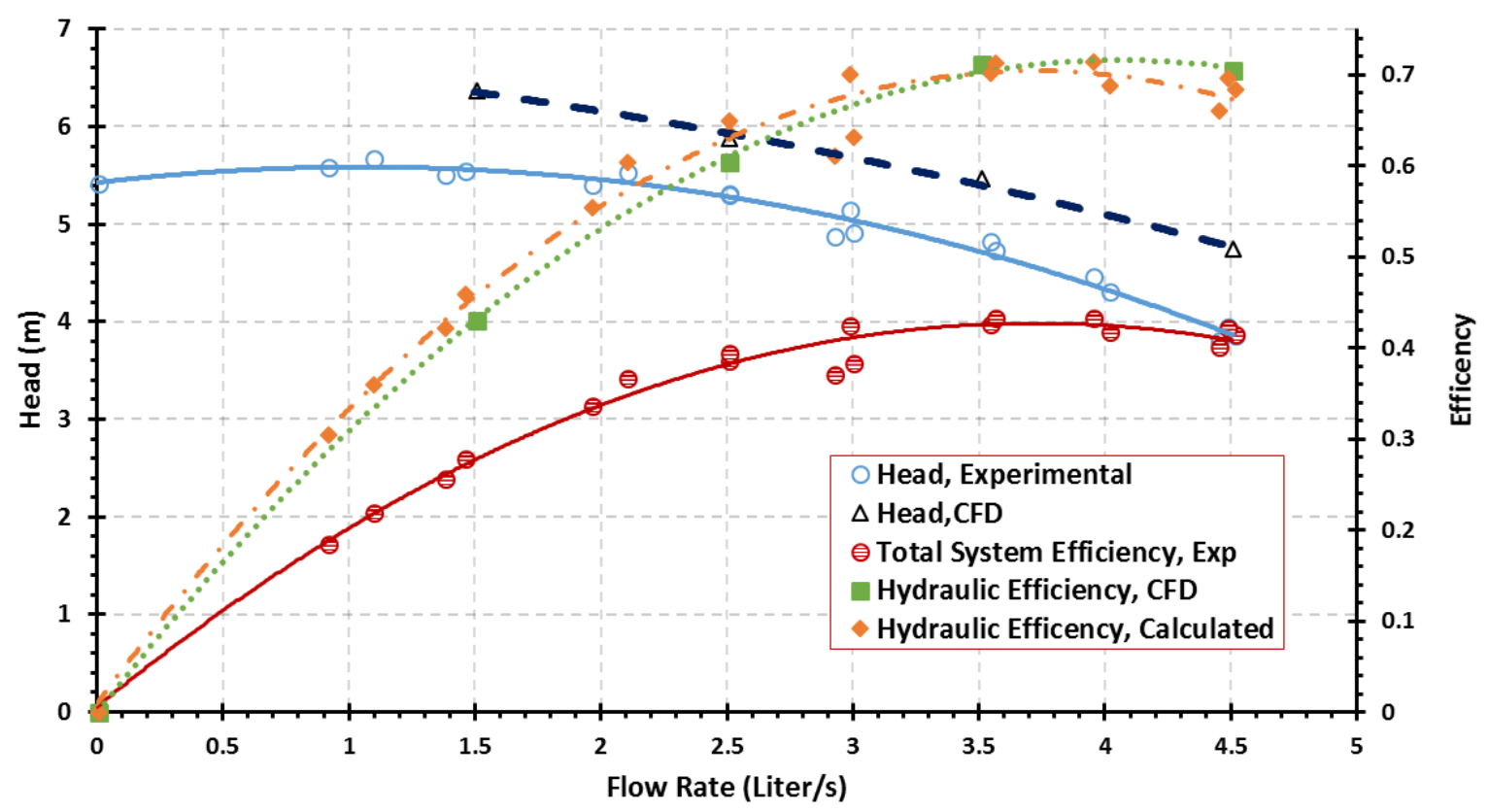

Fig. 10. Experimental vs CFD for side clearance e $=1 \mathrm{~mm}$

Under the assumption of no volumetric leakage and the geometrical value approximation the $10 \%$ difference between the CFD head and the experimental head is accepted. And from the efficiency point of view we can calculating the hydraulic efficiency from the total system efficiency using the electric motor efficiency $\eta_{e}=0.82$, the mechanical efficiency $\eta_{m}=$ 0.85 and the volumetric efficiency $\eta_{v}=0.87$. The CFD and experimental hydraulic efficiency shows a good agreement. 


\section{Results and Discussions}

\section{Performance curves}

Four cases have been studied to cover the side clearance effect on the centrifugal pump performance, these cases represent three different side clearance width $(e=$ 1,2 and $3 \mathrm{~mm}$ ), and finally are compared with the centrifugal pump with closed impeller. The centrifugal pump performance is illustrated in Fig. 11 and Fig. 12. At these two figures the pump head and efficiency are plotted starting from $Q=0.25 Q_{B E P}$ because the CFD solution cannot predict the performance below this value due to the convergence problem [9]. The side clearance has a regression effect on the centrifugal pump performance. When the side clearance increase the head and efficiency are decrease and the best efficient point (BEP) shifted to the left corresponding to lower flow rate as shown in Fig. 13 and Fig. 14. Also the same figures compare the CFD results with the analytical equations of the head and efficiency reductions, equations (7) and (8) [4]. These equation discuss the reductions of the head and efficiency at the BEP while the CFD solution discuss these reductions for different flow rates.

$$
\begin{gathered}
\frac{H_{e=0}-\mathrm{H}_{e}}{H_{e=0}}=\frac{2.5 \frac{e}{D_{2}}}{\sqrt{\frac{b_{2}}{D_{2}}\left(1-\frac{D_{1}}{D_{2}}\right) Z}\left(\frac{t Z}{\pi D_{2}}\right)^{0.2}\left(\frac{n \sqrt{Q_{B E P}}}{H_{B E P}^{0.75}}\right)^{0.1}\left(\sin \beta_{2}\right)^{1.2}\left(\sin \beta_{1}\right)^{0.4}} \\
\frac{\eta_{e=0}-\eta_{e}}{\eta_{e=0}}=\frac{2}{3} \frac{H_{e=0}-\mathrm{H}_{e}}{H_{e=0}}
\end{gathered}
$$

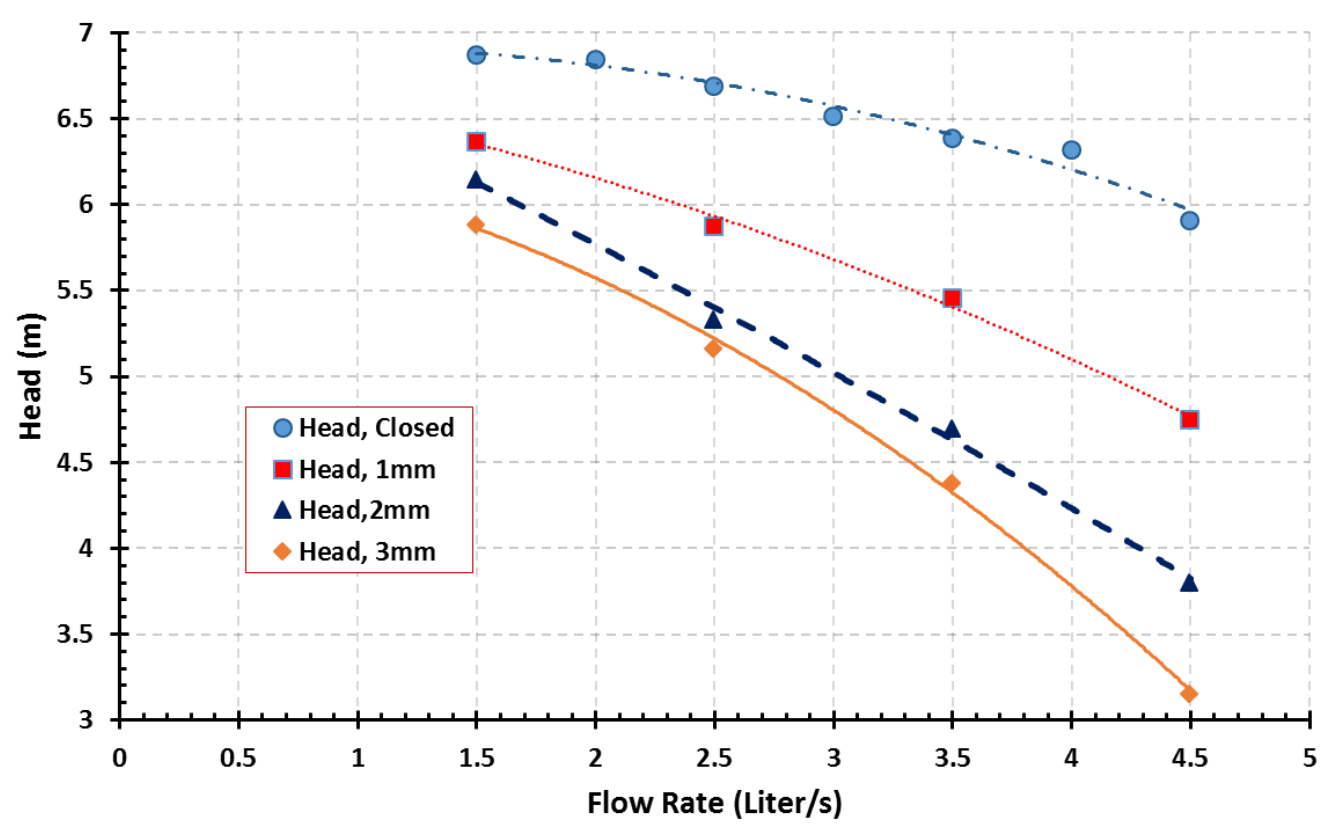

Fig. 11. Centrifugal pump head at different flow rates, CFD 


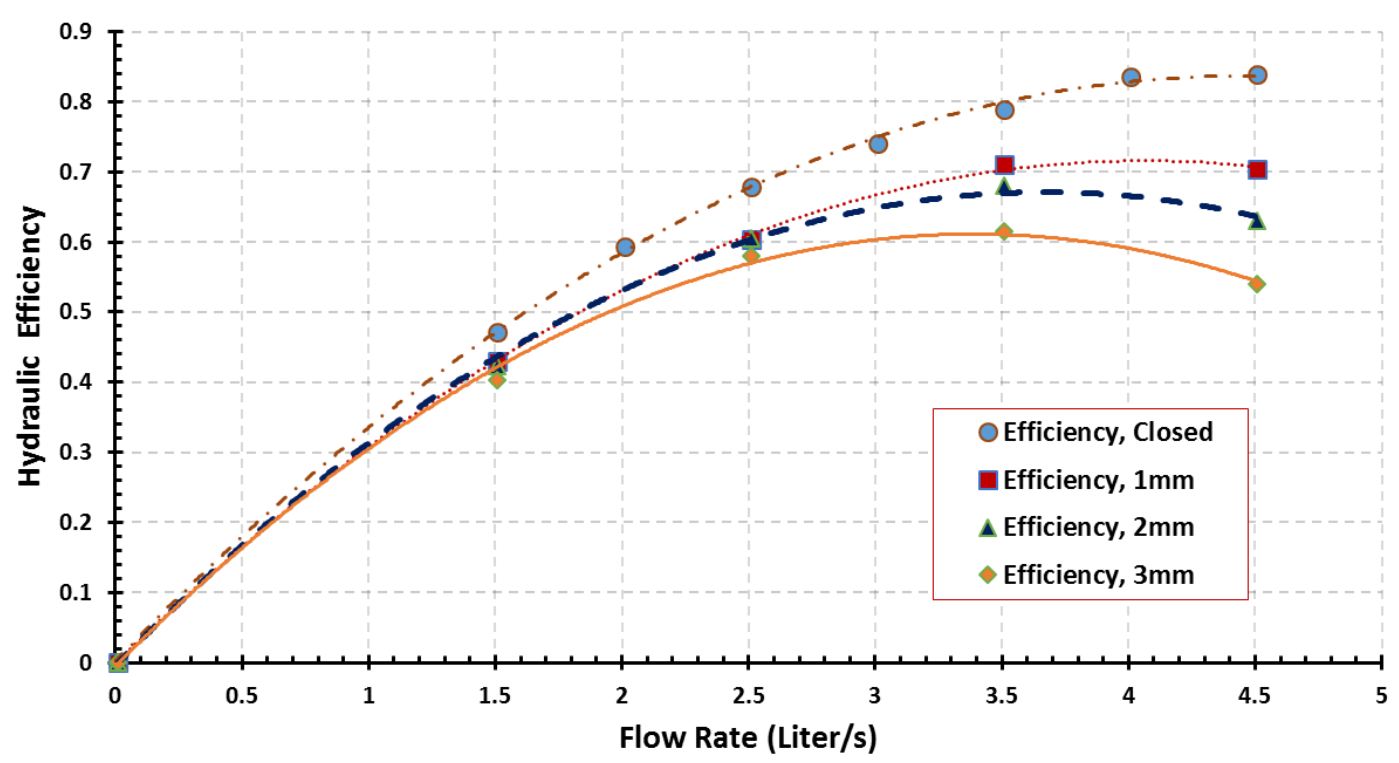

Fig. 12. Centrifugal Pump Efficiency at different flow rate, CFD

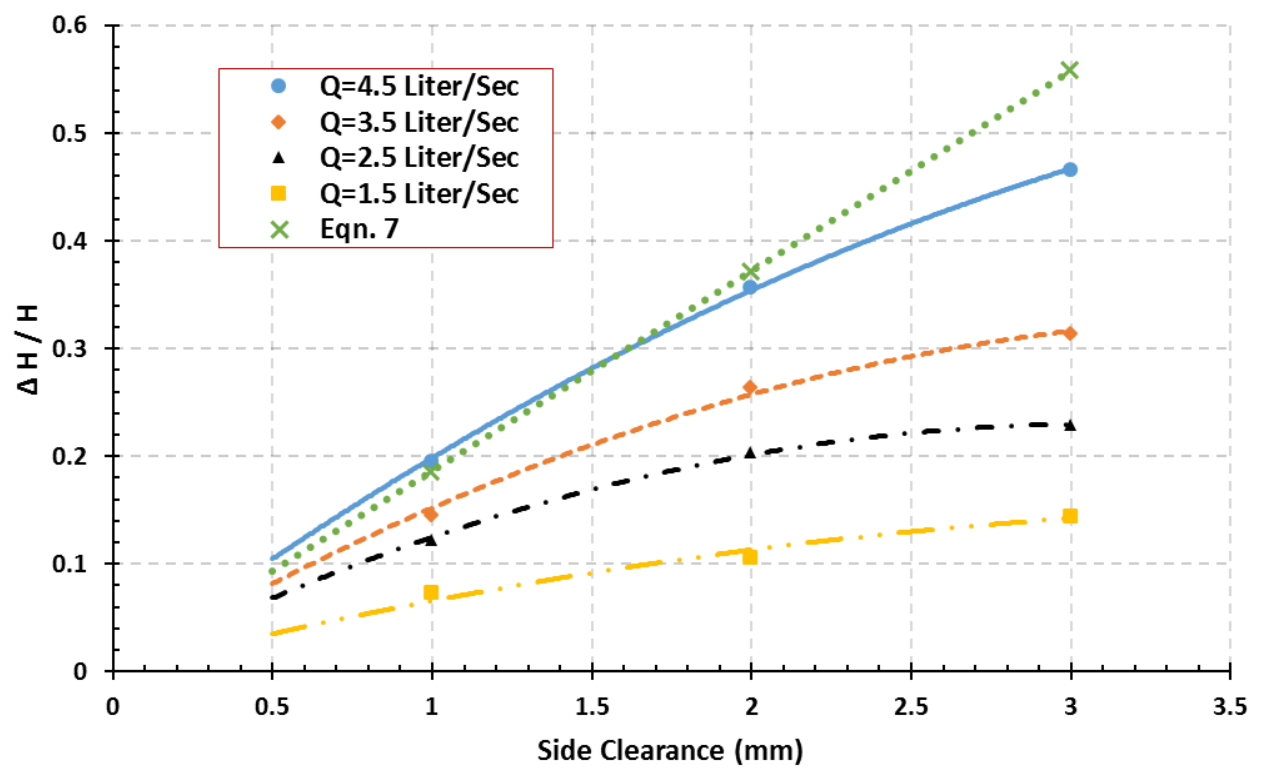

Fig. 13. Change of the pump head with increasing the side clearance width, CFD

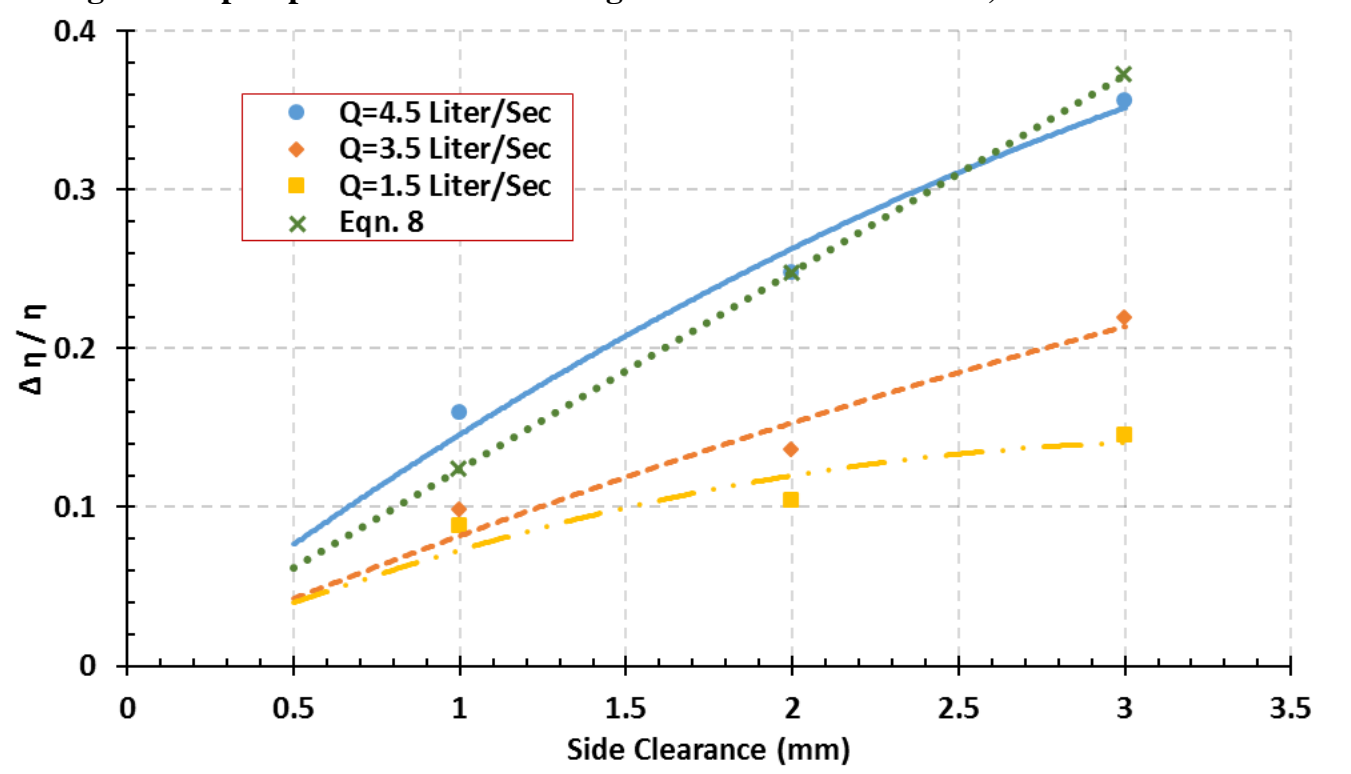

Fig. 14. Change of the pump efficiency with increasing the side clearance width, CFD 
A summary of the pump performance for different side clearance width at flow rate $Q=$ $3.5 \mathrm{Liter} / \mathrm{s}$ are shown in Table 3 , the torque at the impeller blades and walls $\left(M_{i m p}\right)$ are calculating from equation (9) [10], while the theoretical head from power $\left(H_{i m p}\right)$ and the theoretical head for infinite number of blades $\left(H_{t h \infty}\right)$ is calculated using equation (10) and (11), also the hydraulic efficiency are calculated from the relations (12) [11]. As noticed with increasing pump side clearance the blade torque and the hydraulic efficiency decrease.

Fluid slip is the deviation in the angle at which the fluid leaves the impeller $\left(\beta_{2}^{\prime}\right)$ from the blade's exit angle $\left(\beta_{2}\right)$ as shown in Fig. 15 (a); we can represent this phenomenon by means of slip factor. Numerically, there are two expressions to calculate the slip factor [11]. The first expression using the velocity triangle to calculate the slip factor. While, the second expression is derived from the theoretical head as shown in the equations (13), (14) respectively. The conclusion from the two expressions is the slip factor decreases with increases the slide clearance width as shown in Fig. 16. The main reason for the drop in slip factor is with increase the side clearance width the average circumferential absolute velocity at the impeller outlet $\left(C_{u 2}\right)$ decreases as shown in Fig. 15 (b).

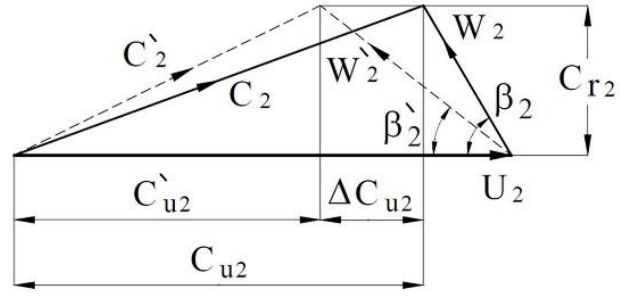

(a)

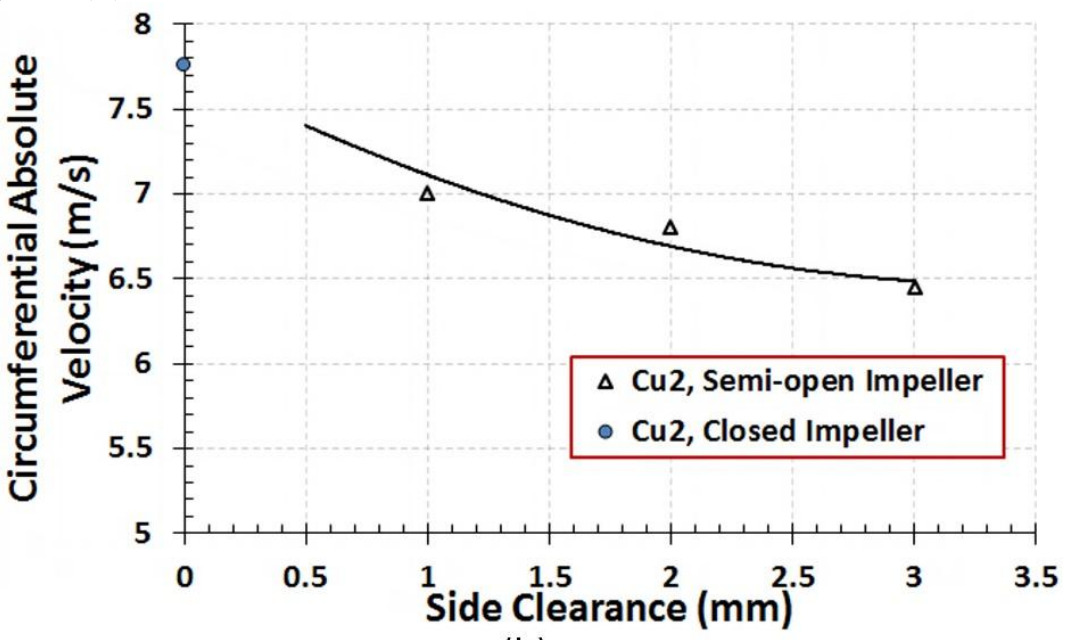

(b)

Fig. 15 (a) Velocity triangle at impeller outlet

(b) effect of side clearance on the $C_{u 2}$ $\mathrm{Q}=3.5 \mathrm{Liter} / \mathrm{s}$

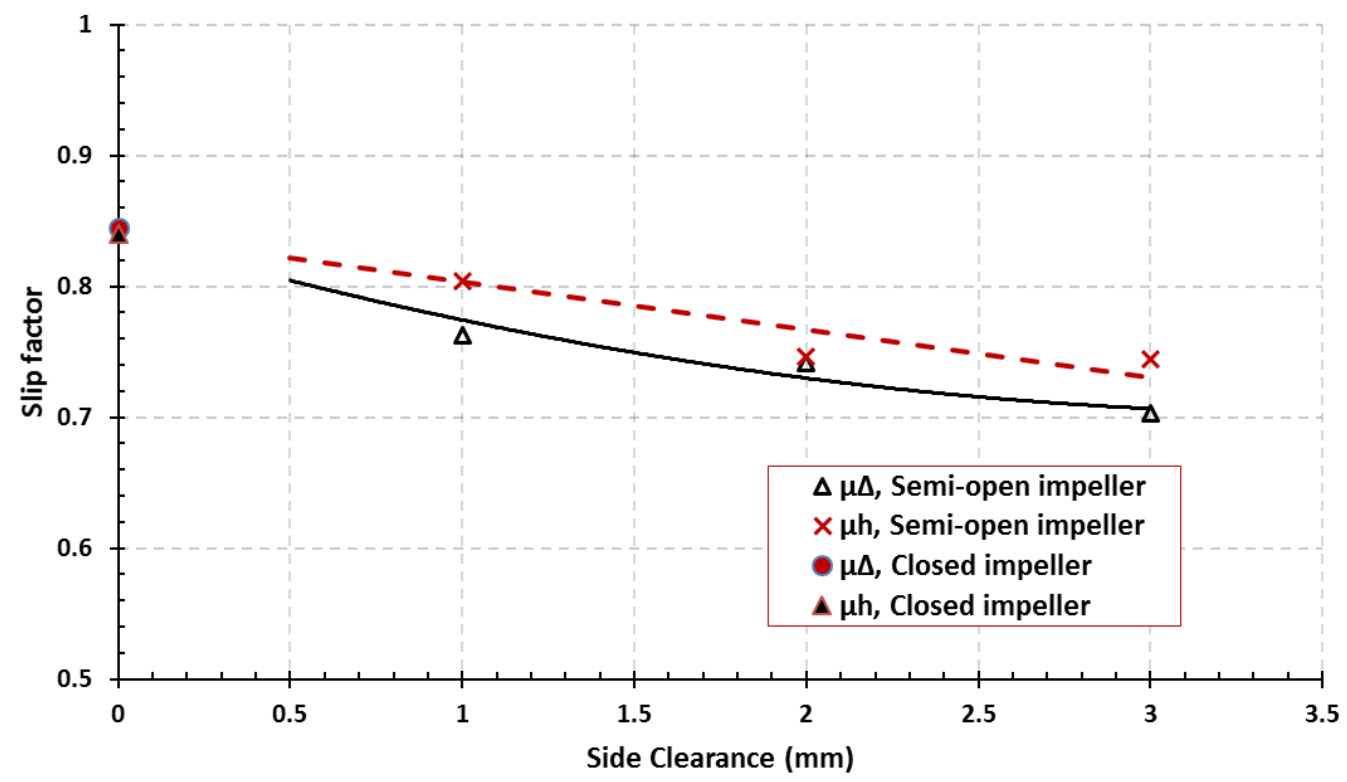

Fig. 16. The effect of side clearance width on the slip factor $Q=3.5$ liter/s

$$
\begin{gathered}
M_{i m p}=\int_{r_{1}}^{r_{2}}\left[(\vec{r} \times \vec{n}) \cdot p+\left(\vec{r} \times \overrightarrow{\tau_{w}}\right) \cdot \cot \beta\right] \cdot b \cdot d r \\
H_{i m p}=P_{i m p} / \rho g Q_{i m p}=\omega \cdot M_{u} / \rho g Q_{i m p}
\end{gathered}
$$




$$
\begin{gathered}
H_{t h \infty}=\frac{U_{2} C_{u 2}-U_{1} C_{u 1}}{g} \\
\eta_{h}=H / H_{i m p} \\
\mu_{\Delta}=C_{u 2} / C_{u 2} \\
\mu_{H}=H_{i m p} / H_{t h \infty}
\end{gathered}
$$

\begin{tabular}{|c|c|c|c|c|c|c|c|c|c|}
\hline \multirow{2}{*}{$\begin{array}{c}\text { Side } \\
\text { Clearance } \\
(\mathbf{m m}) \\
\end{array}$} & \multirow{2}{*}{$\begin{array}{l}\text { Torque } \\
M_{u} \\
(\mathrm{~N} \mathrm{~m}) \\
\end{array}$} & \multirow{2}{*}{$\begin{array}{l}\text { Impeller } \\
\text { Power } \\
\text { (Watt) }\end{array}$} & \multirow{2}{*}{$\begin{array}{l}\text { Output } \\
\text { Power } \\
\text { (Watt) } \\
\end{array}$} & \multirow{2}{*}{$\begin{array}{c}\boldsymbol{H} \\
(\boldsymbol{m})\end{array}$} & \multirow{2}{*}{$\begin{array}{l}H_{i m p} \\
\text { (m) }\end{array}$} & \multirow{2}{*}{$\begin{array}{c}H_{t h \infty} \\
(\mathbf{m})\end{array}$} & \multirow{2}{*}{$\begin{array}{l}\text { Haydraulic } \\
\text { efficiency } \eta_{h}\end{array}$} & \multicolumn{2}{|c|}{ Slip Factor } \\
\hline & & & & & & & & $\mu_{H}$ & $\boldsymbol{\mu}_{\Delta}$ \\
\hline $\mathbf{0}$ & 1.755 & 275.68 & 219.11 & 6.38 & 8.03 & 9.56 & 0.795 & 0.840 & 0.845 \\
\hline 1 & 1.678 & 263.62 & 187.27 & 5.46 & 7.68 & 9.56 & 0.711 & 0.803 & 0.763 \\
\hline 2 & 1.558 & 244.83 & 161.21 & 4.7 & 7.13 & 9.56 & 0.659 & 0.746 & 0.741 \\
\hline 3 & 1.555 & 244.27 & 150.28 & 4.38 & 7.12 & 9.56 & 0.615 & 0.745 & 0.702 \\
\hline
\end{tabular}

Table 3 impeller performance at $Q=3.5 \mathrm{Liter} / \mathrm{s}$

\section{Effect of side clearance on the pressure field}

One of the main reasons for the performance regression is the decreasing of the pressure difference between the impeller inlet and outlet as shown in the blade loading curve, Fig. 17. This pressure drop may attributed to opposition from secondary flow which pass throw the blade tip to the main flow.

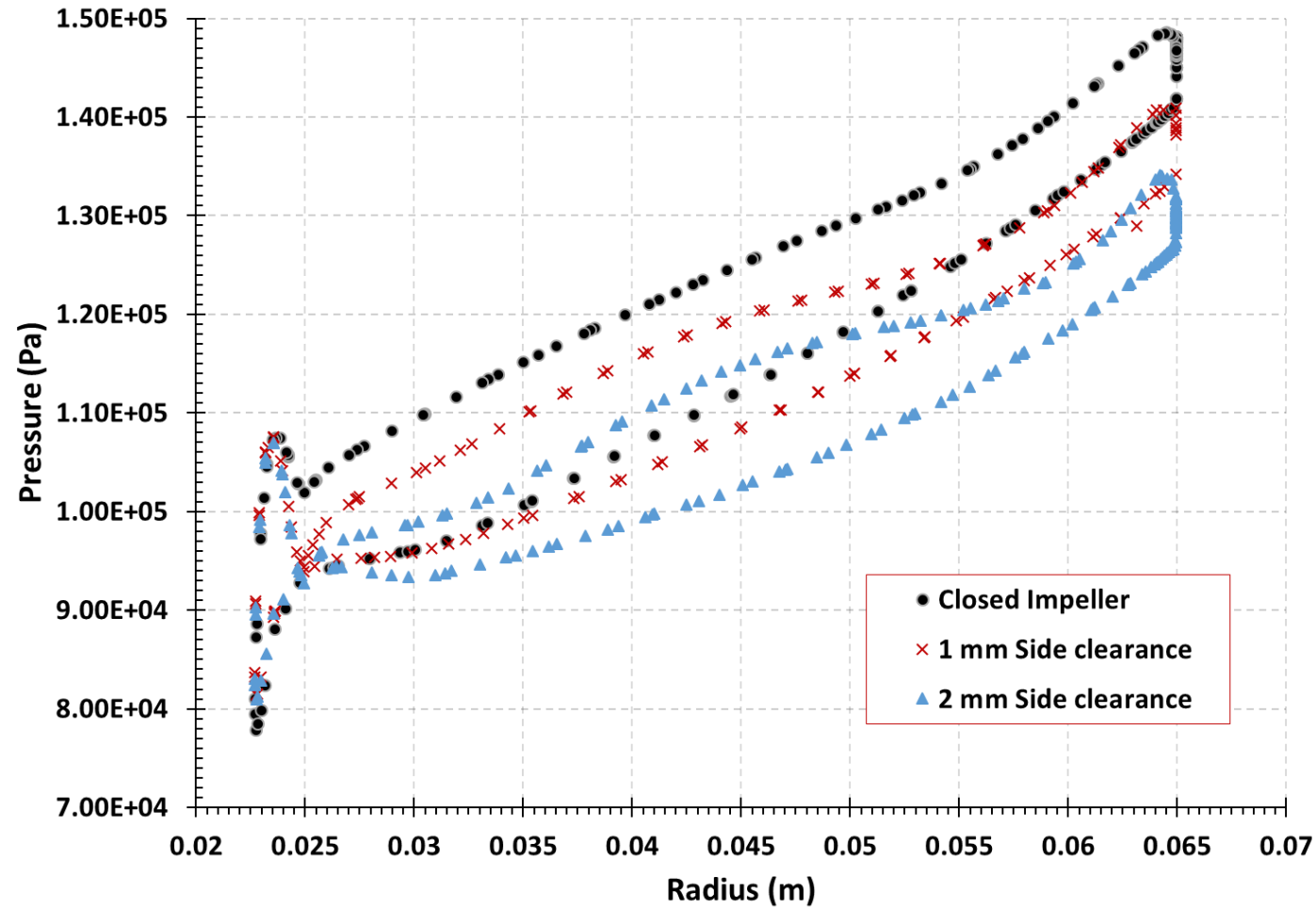

Fig. 17. Impeller blade loading at flow rate $Q=3.5 \mathrm{Liter} / \mathrm{s}$ (mid span) 


\section{Conclusions}

In the present work, a parametric study is attempted, based on the Impeller side clearance to investigate the effect of the clearance width on the pump performance, the following are concluded:

- The impeller side clearance have a great regression effect on the centrifugal pump performance. The reduction in the head and efficiency is function of the side clearance width at different flow rate.

- One of the main causes of the performance reduction is the falling-off in the blade loading which leading to decreasing the pressure rise in the impeller.

- Due to the decay in the blade loading the torque at the blades decreases causes a drops in the impeller input power.

- Due to the reduction in the circumferential component of the absolute velocity at the impeller outlet the slip factor decreases with incresing the side clearance width.

\section{References}

[1] A. J. Stepanoff, Centrifugal and axial flow pumps: John Wiley \& Sons, 1957.

[2] W. Robert, S. Stephen, C. Wei-Chung, and W. Morgan, "Comparison of unshrouded impeller analysis and experiment," presented at the 37th Joint Propulsion Conference and Exhibit, 2001.

[3] (3 Jan 2015). Mc Nally's Pump and Seal School. Available: http://www.mcnallyinstitute.com/14-html/14-02.htm

[4] J. F. Gülich, Centrifugal pumps: Springer, 2010.

[5] S. Aknouche, "Impact of Tip Clearance Flow on Centrifugal Impeller Pump Performance," Master of Science, Massachusetts Institute of Technology, Cambridge, 2003.

[6] "ANSYS® 14.5.7 CFX-Solver Theory Guide," 2012.

[7] A. F. Ayad, H. M. Abdalla, and A. S. A. El-Azm, "3-D Numerical Study of The Effect of Impeller Blades Slot on The Centrifugal Pump Performance Using CFD," presented at the 16th International Conference on Applied Mechanics \& Mechanical Engineering, Egypt, 2014.

[8] M. Shojaeefard, M. Tahani, M. Ehghaghi, M. Fallahian, and M. Beglari, "Numerical study of the effects of some geometric characteristics of a centrifugal pump impeller that pumps a viscous fluid," Computers \& Fluids, vol. 60, pp. 61-70, 2012.

[9] H. Liu, X. Wu, and M. Tan, "Numerical investigation of the inner flow in a centrifugal pump at the shut-off condition," Journal of Theoretical and Applied Mechanics, vol. 51, 2013.

[10] J. S. Anagnostopoulos, "A fast numerical method for flow analysis and blade design in centrifugal pump impellers," Computers \& Fluids, vol. 38, pp. 284-289, 2009.

[11] W. Li, "Effects of Flow Rate and Viscosity on Slip Factor of Centrifugal Pump Handling Viscous Oils," Pump technology, 2013. 